\title{
Ultraviolet-LED irradiation effectively detoxified aflatoxin B1 in groundnut oils
}

Haibo Wang ${ }^{\mathrm{a}}$, Changbao $\mathrm{Li}^{\mathrm{b}, \mathrm{c}, *}$, Ming Xin ${ }^{\mathrm{b}, \mathrm{c}}$, Hock Eng Khoo ${ }^{\mathrm{b}, \mathrm{d}}$, Zimei Mo ${ }^{\mathrm{a}}$, Songyu Zhou ${ }^{\mathrm{a}}$, Xiangdong Dai ${ }^{\mathrm{a}}$, Xiaocong Chen ${ }^{\mathrm{a}}$, Yiqing Nong ${ }^{\mathrm{a}}$, Juan-mei Zheng ${ }^{\mathrm{a}}$

a Guangxi-ASEAN Food Inspection and Testing Center, Nanning 530021 China

b Agro-Food Science and Technology Research Institute, Guangxi Academy of Agricultural Sciences, Nanning 530007 China

c Guangxi Key Laboratory of Fruits and Vegetables Storage-processing Technology, Nanning 530007 China

${ }^{d}$ Department of Nutrition and Dietetics, Faculty of Medicine and Health Sciences, Universiti Putra Malaysia, Selangor, Malaysia

*Corresponding author, e-mail: changbaoli@gxaas.net

Received $17 \mathrm{Feb} 2020$

Accepted 8 Aug 2020

\begin{abstract}
This study aimed to evaluate the quality of aflatoxin B1-detoxified unrefined groundnut oils. Detoxification of aflatoxin B1 (AFB1) in unrefined groundnut oils was performed by ultraviolet light-emitting diodes (UV-LED) irradiation. Ten samples of unrefined groundnut oils were subjected to UV-LED treatment before the measurements of AFB1 content, fatty acid compositions and chemical properties. The 20-min treatment reduced AFB1 content by 99\%. Both acid and peroxide values of the oil samples showed little changes after the samples were treated with UV-LED irradiation. GC-MS results showed that 21 types of fatty acid were detected in the untreated oil samples. Minor changes in the levels of fatty acid were also observed after the 20-min treatment. The results proved that UV-LED irradiation effectively reduced AFB1 content in the unrefined groundnut oils and maintained the oil quality. It is a promising strategy for detoxification of AFB1 in groundnut oil.
\end{abstract}

KEYWORDS: Aspergillus flavus, fatty acid methyl esters, UV irradiation, aflatoxin, groundnut oils

\section{INTRODUCTION}

Aspergillus flavus and its metabolite aflatoxins (AFTs) pose health threats to humans, such as intoxication and cancers [1]. The fungus also contributes to huge economic losses in food, aquaculture and animal husbandry industries [2,3]. Food crops are highly susceptible to AFT contamination during production, processing and transportation [4]. Aspergillus flavus contaminations in groundnut, soya bean and other food crops have been attributed to high environmental temperature and humidity.

Groundnut oil contains a range of unsaturated fatty acids and polyphenols. It is widely used as edible oil worldwide. The consumption of groundnut oil in China has increased from 2.81 million metric tonnes in 2016 to 3.08 million metric tonnes in 2019. It is considered an essential type of edible oil among the Chinese. In the rural areas of China, unrefined groundnut oil is highly used by the local communities for cooking food. The oil is prone to AFT contamination [5]. As reported in the literature, AFT contamination in unrefined edible oils available in Guangxi was a serious issue [6]. The report stated that unrefined edible oils, especially home-produced unrefined groundnut oils, were highly contaminated with aflatoxin B1 (AFB1). A recent study showed that unrefined groundnut oils produced locally in Guangdong Province of China were highly contaminated by AFB1 [7]. Therefore, the issue of AFT contamination in the unrefined groundnut oil is worrying. Agricultural scientists need to develop an effective and economical method for removing or detoxifying AFTs without affecting the quality of groundnut oil. On top of groundnut oil, AFT contamination in other edible oils is alarming. Hence, oil refining is a crucial step in detoxification of AFTs.

At present, there are three methods to detoxify AFTs in groundnut oil: physical, chemical and biotechnological [8-10]. Chemical treatment with chlorinating agents, oxidising agents or $75 \%$ methanol has effectively reduced AFTs content. However, the chemical residues pose as a major problem which limits its application in food industry. Application of ultraviolet (UV) radiation 
in food industry replaces the use of dangerous chemicals. UV disinfection sources consist of primarily low-pressure and medium-pressure mercury lamps, which emit monochromatic and polychromatic lights, respectively. However, there are multiple drawbacks associated with the usage of UV light, which include large equipment size, high heat emission and high energy consumption, as well as the presence of mercury in foods [11].

Light-emitting diode (LED) has been used in highly efficient UV decontamination technology. UV-LED emits monochromatic light, which enables customised UV-LED detoxification system at specific wavelengths to be developed. The heat emission from LED is far lower than the traditional UV lamps. Thus, it is more suitable for application in food treatment, and it consumes less energy than the UV lamps [11]. UV irradiation is a popular method because of its high-energy. UV light induces complex photochemical reactions with AFTs. Literature has shown that UV irradiation is a cost-effective technique for detoxifying AFTs in biological samples $[12,13]$. Previous studies also reported that UV irradiation reduced more than $90 \%$ of AFB1 in food products $[12,14,15]$.

To date, there has been no report on the application of UV-LED irradiation technology for detoxification of AFTs in groundnut oil. Due to the seriousness of AFT contamination in unrefined groundnut oil and the health risk associated with dietary exposure to AFB1, there is a need to screen and evaluate AFB1 content and quality of the unrefined groundnut oil selling at the farmers' markets in Guangxi, China. In this study, we developed a novel method for detoxifying AFB1 in the unrefined groundnut oils using a patented AFT degradation machine. This machine has already been invented by applying UVLED irradiation technology. Detoxification of AFB1 in unrefined groundnut oils was done according to the method developed, and the effects of UV-LED irradiation on qualities of the groundnut oils were determined.

\section{MATERIALS AND METHODS}

\section{Chemicals, reagents and apparatus}

AFB1 standard solution $\left(\mathrm{C}_{17} \mathrm{H}_{12} \mathrm{O}_{6}\right.$, CAS No: 1162 $65-8,2 \mu \mathrm{g} / \mathrm{ml}$ ) and immunoaffinity column were obtained from Romer Labs China Ltd. (Beijing, China). BePure ${ }^{\circledR}$ fatty acid methyl ester (FAME) standards (purity $\geqslant 99.0 \%$ ) were purchased from Bestown (Beijing, China). Ultrapure water was prepared from a Milli-Q ultrapure water machine (Mil- lipore Corporation, Milford, MA, USA). Reagents including methanol, $n$-heptane, acetonitrile and formic acid were of HPLC grade, and they were obtained from Merck Chemicals (Shanghai) Co., Ltd. (Shanghai, China). The others analytical grade reagents and chemicals including isooctane, nhexane, diethyl ether, anhydrous sodium sulphate, sodium hydrogen sulphate and potassium hydroxide $(\mathrm{KOH})$ were purchased from Sinopharm Chemical Reagent Co., Ltd. (Shanghai, China).

\section{Samples preparation}

Commercially available samples of unrefined groundnut oils were used in this AFTs detoxification study. The oil samples were randomly collected from ten different locations of farmers' markets in Guangxi during the summer season of 2019. Origins of the oils are shown in Table 1. Freshly collected oil samples were weighed and subjected to UV-LED irradiation. AFB1 stock solution was prepared by diluting the standard solution with methanol to $100 \mathrm{ng} / \mathrm{ml}(0.05 \mathrm{ml} / \mathrm{ml}$ in methanol). The stock solution was stored at $-20^{\circ} \mathrm{C}$ before HPLC analysis. A series of working standard solutions were prepared by diluting the stock solution with methanol at the following concentrations: $0.1,0.5$, $1.0,2.5,5.0,10.0$ and $20.0 \mathrm{ng} / \mathrm{ml}$. The working standard solutions of different concentrations were used for plotting standard calibration graph.

An analytical sample was prepared by mixing $1.0 \mathrm{~g}$ oil with $20 \mathrm{ml}$ of methanol-water $(70: 30, \mathrm{v} / \mathrm{v})$. The mixture was swirled for 20 min using a benchtop orbital shaker and then centrifuged for $10 \mathrm{~min}$ at $10000 \mathrm{rpm}$. Then $4 \mathrm{ml}$ of the supernatant was transferred to a new tube and mixed with $23 \mathrm{ml}$ of PBS containing 1\% TritonX-100. The sample solution was finally injected onto an immunoaffinity column at a flow rate of $1.0 \mathrm{ml} / \mathrm{min}$; the column was rinsed with $10 \mathrm{ml}$ of ultrapure water twice. The adsorbed components were eluted with $1 \mathrm{ml}$ of methanol twice. The eluent was collected in a tube and evaporated to dryness under a stream of nitrogen at a temperature of $50^{\circ} \mathrm{C}$. The dried residue was dissolved with $1.0 \mathrm{ml}$ of mobile phase and filtered through a $0.22 \mu \mathrm{m}$ Millex ${ }^{\circledR}$ GP syringe filter (Merck Millipore Ltd., Carrigtohill, Ireland).

\section{Treatment of unrefined groundnut oils with UV-LED irradiation}

Unrefined groundnut oils with different concentrations of AFB1 were treated using an AFT degradation machine with a UV-LED detoxification system, 
Table 1 AFB1 contents of unrefined groundnut oils treated at different irradiation times.

\begin{tabular}{|c|c|c|c|c|c|c|c|}
\hline \multirow{2}{*}{ Sample } & \multicolumn{6}{|c|}{ AFB1 content $(\mu \mathrm{g} / \mathrm{kg})$} & \multirow{2}{*}{$\begin{array}{l}\text { Origin of } \\
\text { groundnut oils }\end{array}$} \\
\hline & $0 \mathrm{~s}$ & $60 \mathrm{~s}$ & $120 \mathrm{~s}$ & $300 \mathrm{~s}$ & $600 \mathrm{~s}$ & $1200 \mathrm{~s}$ & \\
\hline$\overline{1}$ & $261.3 \pm 1.12^{\mathrm{a}}$ & $10.9 \pm 1.56^{\mathrm{b}}$ & $1.1 \pm 2.45^{\mathrm{c}}$ & $0.0 \pm 0.00^{d}$ & $0.0 \pm 0.00^{\mathrm{d}}$ & $0.0 \pm 0.00^{\mathrm{d}}$ & Myanmar \\
\hline 2 & $147.9 \pm 1.25^{\mathrm{a}}$ & $25.3 \pm 1.54^{\mathrm{b}}$ & $6.8 \pm 2.34^{c}$ & $0.0 \pm 0.00^{\mathrm{d}}$ & $0.0 \pm 0.00^{\mathrm{d}}$ & $0.0 \pm 0.00^{\mathrm{d}}$ & Hubei, China \\
\hline 3 & $1292.9 \pm 0.53^{\mathrm{a}}$ & $627.4 \pm 1.01^{\mathrm{b}}$ & $449.5 \pm 1.21^{\mathrm{c}}$ & $273.7 \pm 1.03^{\mathrm{d}}$ & $114.3 \pm 1.11^{\mathrm{e}}$ & $18.2 \pm 1.55^{\mathrm{f}}$ & Henan, China \\
\hline 4 & $130.5 \pm 1.01^{\mathrm{a}}$ & $12.7 \pm 1.52^{\mathrm{b}}$ & $0.7 \pm 2.64^{c}$ & $0.4 \pm 2.65^{c}$ & $0.2 \pm 2.34^{\mathrm{c}}$ & $0.1 \pm 2.64^{\mathrm{c}}$ & Vietnam \\
\hline 5 & $13.3 \pm 2.33^{\mathrm{a}}$ & $0.0 \pm 0.00^{\mathrm{b}}$ & $0.0 \pm 0.00^{\mathrm{b}}$ & $0.0 \pm 0.00^{\mathrm{b}}$ & $0.0 \pm 0.00^{\mathrm{b}}$ & $0.0 \pm 0.00^{\mathrm{b}}$ & Vietnam \\
\hline 6 & $653.5 \pm 0.24^{\mathrm{a}}$ & $96.4 \pm 1.24^{\mathrm{b}}$ & $20.0 \pm 1.03^{c}$ & $0.0 \pm 0.00^{\mathrm{d}}$ & $0.0 \pm 0.00^{\mathrm{d}}$ & $0.0 \pm 0.00^{\mathrm{d}}$ & Henan, China \\
\hline 7 & $98.1 \pm 1.34^{\mathrm{a}}$ & $7.2 \pm 2.55^{\mathrm{b}}$ & $0.0 \pm 0.00^{c}$ & $0.0 \pm 0.00^{c}$ & $0.0 \pm 0.00^{c}$ & $0.0 \pm 0.00^{c}$ & Vietnam \\
\hline 8 & $101.4 \pm 1.13^{\mathrm{a}}$ & $7.8 \pm 2.34^{b}$ & $1.0 \pm 1.62^{\mathrm{c}}$ & $0.0 \pm 0.00^{\mathrm{d}}$ & $0.0 \pm 0.00^{\mathrm{d}}$ & $0.0 \pm 0.00^{\mathrm{d}}$ & Henan, China \\
\hline 9 & $389.1 \pm 0.88^{\mathrm{a}}$ & $46.0 \pm 1.56^{\mathrm{b}}$ & $5.1 \pm 1.34^{\mathrm{c}}$ & $0.0 \pm 0.00^{\mathrm{d}}$ & $0.0 \pm 0.00^{\mathrm{d}}$ & $0.0 \pm 0.00^{\mathrm{d}}$ & Hubei, China \\
\hline 10 & $70.2 \pm 1.24^{\mathrm{a}}$ & $2.3 \pm 2.55^{\mathrm{b}}$ & $0.0 \pm 0.00^{\mathrm{c}}$ & $0.0 \pm 0.00^{\mathrm{c}}$ & $0.0 \pm 0.00^{c}$ & $0.0 \pm 0.00^{c}$ & South Africa \\
\hline
\end{tabular}

All data were presented as mean \pm standard deviation of three replications. Different superscript lowercase letters denote a significant difference $(p<0.05)$. The oil samples were irradiated at the intensity of $3500 \mu \mathrm{W} / \mathrm{cm}^{2}$.

and the patented equipment (Chinese patent number: ZL 20172 0215388.6) was specifically used for treating oil samples. The equipment is produced by the Guangxi Youqing Miyi Technology Co., Ltd. (Guangxi, China). In brief, $10 \mathrm{~g}$ oil sample was placed in a $25 \mathrm{ml}$ glass colourimetric tube. The sample was exposed to UV-LED irradiation intensity of $3500 \mu \mathrm{W} / \mathrm{cm}^{2}$ for $10-1200 \mathrm{~s}$. UV-LED light intensity was set by adjusting the distance between colourimeter and UV lamp. The light intensity was measured using a photometer. The intensities of UVLED light $\left(\lambda_{\max }=254 \mathrm{~nm}\right)$ were set at 450,750 , $1250,1550,1850$ and $3500 \mu \mathrm{W} / \mathrm{cm}^{2}$ at distances of $12,10,7,5,2$ and $0 \mathrm{~cm}$, respectively; the irradiation time was set at $60 \mathrm{~s}$. After the treatment, AFB1 content, fatty acid compositions, acid and peroxide values of all oil samples were determined. Triplicate analyses were performed on all samples.

\section{HPLC analysis of AFB1}

Changes in AFB1 content of the oil samples were determined by HPLC after irradiated using the UVLED detoxification system. The filtrate was analysed by an HPLC system (Waters Alliance 2695 Separations Module, Milford, MA, USA) at a flow rate of $0.8 \mathrm{ml} / \mathrm{min}$ using an Agilent ZORBAX SBC18 column $(250 \mathrm{~mm} \times 4.6 \mathrm{~mm}, 5 \mu \mathrm{m})$. Isocratic mobile phase used in separation of AFB1 was a mixture of methanol:acetonitrile:water (35:10:55 $\mathrm{v} / \mathrm{v} / \mathrm{v})$. The column temperature was set at $35^{\circ} \mathrm{C}$, and the injection volume was $20 \mu \mathrm{l}$. Post-column photochemical derivatisation was performed with trifluoroacetic acid, and fluorescence detector was set at an excitation wavelength of $360 \mathrm{~nm}$ and an emission wavelength of $440 \mathrm{~nm}$. A recovery test was done by spiking the untreated oil sample with a known amount of AFB1 standard. Each spiked sample was prepared by mixing $10 \mu \mathrm{g}$ AFB1 standard and $1.0 \mathrm{~g}$ oil sample. Recovery of AFB1 in the oil sample was $90 \pm 4 \%$ based on triplicate measurements.

\section{GC-MS analysis of fatty acids}

Fatty acid compositions of both irradiated and nonirradiated oil samples were determined using a Thermo Scientific TSQ ${ }^{\mathrm{TM}} 9000$ triple quadrupole GC-MS/MS system (Shanghai, China). FAME stock solution was prepared in a 10-ml volumetric flask at a solution concentration of $5.0 \mathrm{mg} / \mathrm{ml}$ in n-heptane. The stock solution was stored in a $-20^{\circ} \mathrm{C}$ freezer before GC analysis. It was found to be remaining stable for over three months.

Analytical samples were prepared by mixing $100 \mathrm{mg}$ oil and $10 \mathrm{ml}$ of $\mathrm{n}$-hexane in a $25-\mathrm{ml}$ glass colourimeter tube. The mixture was agitated for $2 \mathrm{~min}$, followed by the addition of $0.5 \mathrm{ml}$ of $\mathrm{KOH}$-methanol $(0.5 \mathrm{M})$, and then ultrasonicated at a controlled temperature of $40^{\circ} \mathrm{C}$ for $20 \mathrm{~min}$. The mixture, after added with $5 \mathrm{ml}$ of ultrapure water, was transferred to a new centrifuge tube and centrifuged at $10000 \mathrm{rpm}$ for $3 \mathrm{~min}$ at $25^{\circ} \mathrm{C}$. Supernatant obtained was transferred to a conical flask and treated with $2.0 \mathrm{~g}$ anhydrous sodium sulphate to remove excessive water. Before the GCMS analysis, the supernatant was filtered through a $0.22 \mu \mathrm{m}$ Millex® GP syringe filter. GC-MS analysis was performed in duplicate.

GC-MS analysis of fatty acids was performed based on the method provided by the Thermo Fisher Scientific Inc. [16]. Fatty acids in oil samples and FAME mixture were separated by using a TR-FAME $(100 \mathrm{~m} \times 0.25 \mathrm{~mm} \times 0.2 \mu \mathrm{m})$ capillary column. Helium was used as a carrier gas with a flow rate of $1.0 \mathrm{ml} / \mathrm{min} ; 1.0 \mu \mathrm{l}$ injections were made in split mode, with a split ratio of $1: 10$. Injector temperature was also set at $250^{\circ} \mathrm{C}$. Analytes were separated 
at a constant flow with the column temperature programmed at an initial $80^{\circ} \mathrm{C}$ for $2 \mathrm{~min}$ at $30^{\circ} \mathrm{C} / \mathrm{min}$, then $140^{\circ} \mathrm{C}$ for $1 \mathrm{~min}$, and finally, $240^{\circ} \mathrm{C}$ at $2^{\circ} \mathrm{C} / \mathrm{min}$ for $5 \mathrm{~min}$. Ion source temperature and interface temperature were set at $220^{\circ} \mathrm{C}$ and $250^{\circ} \mathrm{C}$, respectively. The solvent delay time was $5.5 \mathrm{~min}$. MS measurement was operated in electron impact (EI) mode and Q3 scan monitoring mode (m/z 40-450). Each peak was identified through comparison with the mass library of NIST 14. Quantitative analysis of fatty acids was done based on area normalisation method [17].

\section{Acid and peroxide values of the unrefined groundnut oils}

Acid and peroxide values are the critical quality attributes of oil samples. The determinations of acid and peroxide values of both irradiated and nonirradiated oil samples were done according to the methods described by Hussin et al [18], which were based on the AOCS Official Method Ca 5a-40 and Method Cd 8b-90, respectively [19,20]. All oil samples were irradiated at an intensity of $3500 \mu \mathrm{W} / \mathrm{cm}^{2}$ for 10, 30, 45, 60, 120, 300, 600 and $1200 \mathrm{~s}$, except for the untreated oil sample. Acid and peroxide values of all oil samples were determined based on titration methods, and the values were expressed as $\mathrm{mg} / \mathrm{g}$ and $\mathrm{mmol} / \mathrm{kg}$, respectively.

\section{Statistical analysis}

All data were presented in means of three replicates, except for the GC-MS data. The mean differences were statistically analysed using Minitab version 15.0 (Minitab Inc., PA, USA). Analysis of variance (ANOVA), coupled with the least significant difference was used for multiple comparisons. Significance was set at $p<0.05$.

\section{RESULTS}

Effects of UV-LED irradiation time and intensity on AFB1 degradation in the unrefined groundnut oils

Working standard solution of AFB1 was injected in triplicate, and the response had high linearity, which showed a linear response range from 0.1 to $20 \mathrm{ng} / \mathrm{ml}\left(R^{2}=0.9999 ; y=2.399 \times 10^{5} x-\right.$ 3463). The concentrations of AFB1 in ten samples of unrefined groundnut oil after the UV-LED treatment are presented in Table 1. The HPLC chromatograms of both sample and standard are shown in Fig. 1. ANOVA data showed that there were significant
(A)

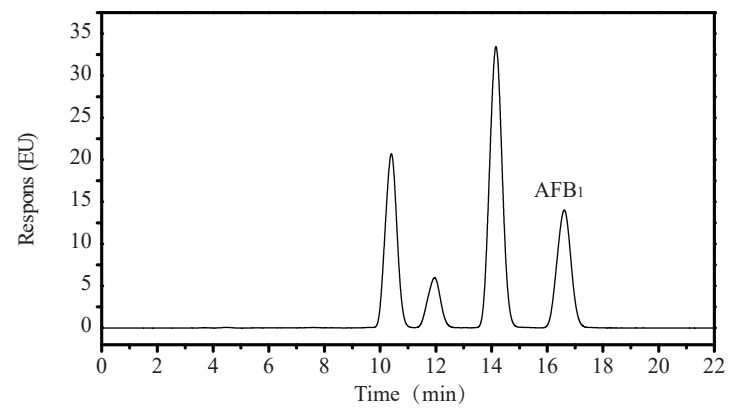

(B)

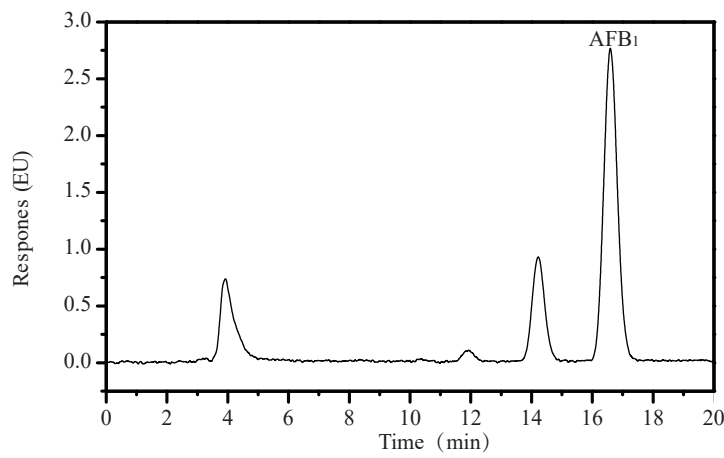

Fig. 1 HPLC chromatograms of (A) aflatoxin standard and (B) AFB1 in groundnut oil.

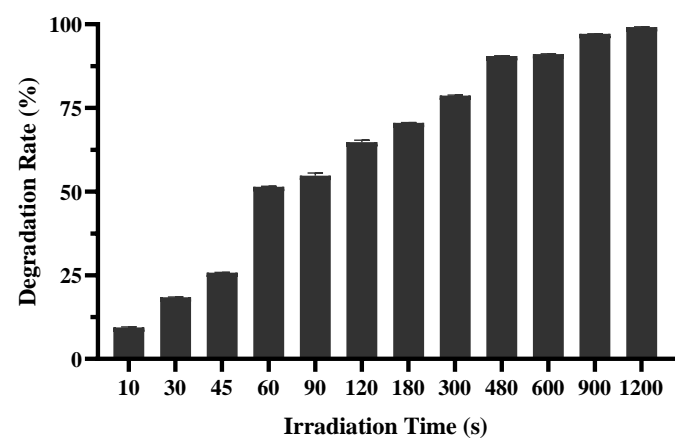

Fig. 2 Degradation rate of groundnut oil (sample 3) by applying irradiation intensity of $3500 \mu \mathrm{W} / \mathrm{cm}^{2}$ at different irradiation times.

reductions in AFB1 content in all oil samples after the irradiations $(p<0.05)$.

As AFB1 absorbed UV, the irradiation activates AFB1 and increases its susceptibility to degradation. After being treated using the AFT degradation machine for different irradiation times at intensity of $3500 \mu \mathrm{W} / \mathrm{cm}^{2}$, we found that the concentration of AFB1 in the oil samples reduced with increasing treatment duration. As AFB1 concentrations in nine 
Table 2 Degradation effects of unrefined groundnut oils treated with different intensities $\left(\mu \mathrm{W} / \mathrm{cm}^{2}\right)$ of UV-LED irradiation.

\begin{tabular}{|c|c|c|c|c|c|c|c|}
\hline \multirow{2}{*}{ Sample } & \multicolumn{7}{|c|}{ AFB1 content $(\mu g / \mathrm{kg})$} \\
\hline & 0 & 450 & 750 & 1250 & 1550 & 1850 & 3500 \\
\hline 1 & $261.3 \pm 0.85^{\mathrm{a}}$ & $118.0 \pm 1.35^{\mathrm{b}}$ & $86.7 \pm 1.22^{c}$ & $75.1 \pm 1.56^{\mathrm{d}}$ & $55.9 \pm 1.54^{\mathrm{e}}$ & $29.9 \pm 2.14^{f}$ & $11.0 \pm 2.55^{g}$ \\
\hline 2 & $147.9 \pm 0.89^{\mathrm{a}}$ & $85.5 \pm 1.04^{b}$ & $79.5 \pm 1.16^{\mathrm{c}}$ & $72.9 \pm 1.11^{\mathrm{d}}$ & $59.9 \pm 1.04^{\mathrm{e}}$ & $60.6 \pm 1.25^{\mathrm{e}}$ & $26.9 \pm 2.34_{f}^{f}$ \\
\hline 3 & $1292.9 \pm 0.15^{\mathrm{a}}$ & $1210.0 \pm 0.21^{\mathrm{b}}$ & $1101.0 \pm 0.14^{\mathrm{c}}$ & $1092.0 \pm 0.16^{c}$ & $1056.0 \pm 0.19^{\mathrm{d}}$ & $989.1 \pm 0.20^{\mathrm{e}}$ & $632.8 \pm 0.33^{f}$ \\
\hline 4 & $130.5 \pm 1.05^{\mathrm{a}}$ & $63.3 \pm 2.01^{b}$ & $44.2 \pm 2.14^{\mathrm{c}}$ & $37.7 \pm 2.47^{c}$ & $22.2 \pm 2.56^{\mathrm{d}}$ & $9.2 \pm 2.54^{\mathrm{e}}$ & $6.7 \pm 2.65^{\mathrm{e}}$ \\
\hline 5 & $13.2 \pm 2.01^{\mathrm{a}}$ & $1.6 \pm 2.55^{\mathrm{b}}$ & $1.2 \pm 2.54^{\mathrm{b}}$ & $1.0 \pm 2.31^{\mathrm{b}}$ & $0.8 \pm 2.54^{b}$ & $0.5 \pm 2.55^{\mathrm{b}}$ & $0.0 \pm 0.00^{c}$ \\
\hline 6 & $653.5 \pm 0.51^{\mathrm{a}}$ & $362.8 \pm 0.58^{\mathrm{b}}$ & $338.9 \pm 0.57^{c}$ & $269.2 \pm 0.56^{\mathrm{d}}$ & $243.6 \pm 0.68^{\mathrm{e}}$ & $139.7 \pm 1.01^{\mathrm{f}}$ & $98.2 \pm 1.58^{g}$ \\
\hline 7 & $98.1 \pm 1.11^{\mathrm{a}}$ & $35.4 \pm 1.25^{\mathrm{b}}$ & $30.4 \pm 1.25^{\mathrm{b}}$ & $20.4 \pm 1.34^{\mathrm{c}}$ & $15.2 \pm 1.56^{\mathrm{d}}$ & $7.8 \pm 2.14^{\mathrm{e}}$ & $7.4 \pm 2.67^{\mathrm{e}}$ \\
\hline 8 & $101.4 \pm 1.02^{\mathrm{a}}$ & $42.6 \pm 2.01^{\mathrm{b}}$ & $38.4 \pm 2.47^{\mathrm{b}}$ & $24.6 \pm 2.56^{c}$ & $23.4 \pm 2.54^{\mathrm{c}}$ & $13.0 \pm 2.34^{\mathrm{d}}$ & $7.9 \pm 2.72^{\mathrm{d}}$ \\
\hline 9 & $389.1 \pm 0.56^{\mathrm{a}}$ & $160.3 \pm 0.68^{b}$ & $142.5 \pm 0.89^{c}$ & $138.3 \pm 0.98^{\mathrm{d}}$ & $76.7 \pm 1.46^{\mathrm{e}}$ & $53.5 \pm 1.89^{f}$ & $46.7 \pm 1.53^{g}$ \\
\hline 10 & $70.2 \pm 1.68^{\mathrm{a}}$ & $23.8 \pm 2.19^{b}$ & $17.3 \pm 2.75^{b, c}$ & $14.0 \pm 2.63^{\mathrm{c}, \mathrm{d}}$ & $10.5 \pm 2.71^{\mathrm{d}}$ & $5.7 \pm 2.65^{\mathrm{d}, \mathrm{e}}$ & $2.5 \pm 2.58^{\mathrm{e}}$ \\
\hline
\end{tabular}

All data were presented as mean \pm standard deviation of three replications. Different superscript lowercase letters denote a significant difference $(p<0.05)$. The oil samples were irradiated for $60 \mathrm{~s}$.

samples of the unrefined groundnut oils were lower than $650 \mu \mathrm{g} / \mathrm{kg}, 2$-min irradiation was enough to reduce AFT levels to $20 \mu \mathrm{g} / \mathrm{kg}$ or lower; no residue of AFB1 was found in the oil samples treated at $300 \mathrm{~s}$ irradiation. Due to the high concentration of AFB1 in sample 3 (up to $1292 \mu \mathrm{g} / \mathrm{kg}$ ), its AFB1 concentration reduced to $273 \mu \mathrm{g} / \mathrm{kg}$ after the $300 \mathrm{~s}$ irradiation (Table 1). The decrement rate was about $80 \%$. Hence, by applying a 20 -min irradiation time, the degradation rate of AFB1 in sample 3 was up to 98\% (Fig. 2).

The unrefined groundnut oils with different AFB1 concentrations were also treated with various irradiation intensities $\left(450-3500 \mu \mathrm{W} / \mathrm{cm}^{2}\right)$ for $60 \mathrm{~s}$. As showed in Table 2, the AFB1 degradation rate was proportional to irradiation intensity. Similarly, the AFB1 degradation rate of sample 3 was much lower than the other samples. The results also showed that the degradation rate was highly correlated with irradiation time and intensity, where the Pearson correlation coefficient $r$-values were $0.8-0.9$.

\section{Influence of UV-LED irradiation on quality of the unrefined groundnut oils}

After the unrefined groundnut oils had been irradiated at different irradiation times and intensities using the UV-LED detoxification system, the temperature of the oils increased about $5^{\circ} \mathrm{C}$ after a 20 -min (1200 s) irradiation. When the irradiation times were below $5 \mathrm{~min}$ (300 s), no changes in the oil temperatures were observed (data not shown). As shown in Tables 3 and 4, there were no significant changes in acid and peroxide values, respectively $(p>0.05)$ after the oil samples were irradiated for $20 \mathrm{~min}$ by applying an irradiation intensity of $3500 \mu \mathrm{W} / \mathrm{cm}^{2}$. The results also indicated that acid and peroxide values of all irradiated oil samples were not significantly different compared to the untreated samples $(p>0.05)$.

In this study, the main nutritional component of the unrefined groundnut oils was fatty acid; therefore, the number of fatty acids can be one of the useful criteria for measuring the quality of the oil samples besides acid and peroxide values. The oil samples were methylated, and fatty acid compositions of the oil samples were determined based on the in-house developed GC-MS method. Types of fatty acids of all oil samples were characterised by comparing retention times and molecular masses of the fatty acids between samples and standard. GC-MS chromatograms of FAME standards and oil sample are shown in Fig. 3.

The untreated groundnut oils had 21 types of fatty acid which included $67.51 \%$ unsaturated fatty acids and $32.49 \%$ saturated fatty acids. Allcis-9,12-octadecadienoic acid (linoleic acid), cis-9octadecenoic acid (oleic acid) and cis-11-eicosenoic acid (gondoic acid) were the three highest unsaturated fatty acids in all samples, whereas hexadecanoic acid (palmitic acid), octadecanoic acid (stearic acid) and docosanoic acid (behenic acid) were the major saturated fatty acids. Considering that the response values of the fatty acid isomers are similar, the relative abundance value of each fatty acid can be determined by the area normalisation method, and the results are shown in Table 5. After being subjected to UV-LED irradiation, minor changes in the fatty acid compositions of all oil samples were observed. Hence, no changes in the percentages of trans-fatty acids in the oil samples were observed. Therefore, UV-LED irradiation did not alter fatty acid compositions of the unrefined groundnut oil. It might be because UV-LED irradia- 
Table 3 Acid values of unrefined groundnut oils treated at different irradiation times.

\begin{tabular}{|c|c|c|c|c|c|c|c|c|c|}
\hline \multirow{2}{*}{ Samp } & \multicolumn{9}{|c|}{ Acid value (mg/g) } \\
\hline & $0 \mathrm{~s}$ & $10 \mathrm{~s}$ & $30 \mathrm{~s}$ & $45 \mathrm{~s}$ & $60 \mathrm{~s}$ & $120 \mathrm{~s}$ & $300 \mathrm{~s}$ & $600 \mathrm{~s}$ & $1200 \mathrm{~s}$ \\
\hline 1 & $1.84 \pm 0.23$ & $1.83 \pm 0.21$ & $1.82 \pm 0.24$ & $1.84 \pm 0.34$ & $1.84 \pm 0.51$ & $1.83 \pm 0.45$ & $1.84 \pm 0.28$ & $1.83 \pm 0.42$ & $1.84 \pm 0.22$ \\
\hline 2 & $1.29 \pm 0.32$ & $1.28 \pm 0.31$ & $1.29 \pm 0.29$ & $1.28 \pm 0.22$ & $1.29 \pm 0.19$ & $1.29 \pm 0.33$ & $1.30 \pm 0.22$ & $1.28 \pm 0.19$ & $1.29 \pm 0.33$ \\
\hline 3 & $12.12 \pm 0.12$ & $12.10 \pm 0.15$ & $12.08 \pm 0.22$ & $12.12 \pm 0.21$ & $12.12 \pm 0.19$ & $12.11 \pm 0.28$ & $12.10 \pm 0.15$ & $12.08 \pm 0.13$ & $12.11 \pm 0.12$ \\
\hline 4 & $2.46 \pm 0.24$ & $2.45 \pm 0.25$ & $2.46 \pm 0.24$ & $2.45 \pm 0.26$ & $2.46 \pm 0.23$ & $2.45 \pm 0.19$ & $2.44 \pm 0.18$ & $2.45 \pm 0.19$ & $2.46 \pm 0.21$ \\
\hline 5 & $0.39 \pm 1.29$ & $0.39 \pm 1.05$ & $0.38 \pm 1.32$ & $0.39 \pm 1.12$ & $0.38 \pm 1.13$ & $0.39 \pm 1.32$ & $0.39 \pm 1.46$ & $0.39 \pm 1.24$ & $0.38 \pm 1.37$ \\
\hline 6 & $5.27 \pm 0.26$ & $5.25 \pm 0.18$ & $5.26 \pm 0.14$ & $5.25 \pm 0.17$ & $5.27 \pm 0.19$ & $5.28 \pm 0.21$ & $5.26 \pm 0.22$ & $5.27 \pm 0.17$ & $5.27 \pm 0.14$ \\
\hline 7 & $2.14 \pm 0.41$ & $2.14 \pm 0.33$ & $2.13 \pm 0.24$ & $2.12 \pm 0.29$ & $2.13 \pm 0.28$ & $2.14 \pm 0.31$ & $2.13 \pm 0.23$ & $2.14 \pm 0.24$ & $2.13 \pm 0.27$ \\
\hline 8 & $1.66 \pm 0.34$ & $1.66 \pm 0.26$ & $1.67 \pm 0.24$ & $1.66 \pm 0.26$ & $1.67 \pm 0.25$ & $1.66 \pm 0.21$ & $1.66 \pm 0.23$ & $1.67 \pm 0.24$ & $1.65 \pm 0.27$ \\
\hline 9 & $3.78 \pm 0.25$ & $3.78 \pm 0.19$ & $3.77 \pm 0.19$ & $3.76 \pm 0.22$ & $3.78 \pm 0.24$ & $3.76 \pm 0.19$ & $3.77 \pm 0.21$ & $3.76 \pm 0.19$ & $3.78 \pm 0.23$ \\
\hline 10 & $4.88 \pm 0.27$ & $4.86 \pm 0.22$ & $4.87 \pm 0.21$ & $4.86 \pm 0.16$ & $4.87 \pm 0.17$ & $4.87 \pm 0.21$ & $4.86 \pm 0.23$ & $4.85 \pm 0.19$ & $4.85 \pm 0.25$ \\
\hline
\end{tabular}

All data were presented as mean \pm standard deviation of three replications. The oil samples were irradiated at the intensity of $3500 \mu \mathrm{W} / \mathrm{cm}^{2}$.

Table 4 Peroxide values of unrefined groundnut oils treated at different irradiation times.

\begin{tabular}{|c|c|c|c|c|c|c|c|c|c|}
\hline \multirow{2}{*}{ Sample } & \multicolumn{9}{|c|}{ Peroxide value (mmol/kg) } \\
\hline & $0 \mathrm{~s}$ & $10 \mathrm{~s}$ & $30 \mathrm{~s}$ & $45 \mathrm{~s}$ & $60 \mathrm{~s}$ & $120 \mathrm{~s}$ & $300 \mathrm{~s}$ & $600 \mathrm{~s}$ & $1200 \mathrm{~s}$ \\
\hline 1 & $0.35 \pm 1.12$ & $0.34 \pm 1.13$ & $0.35 \pm 1.02$ & $0.35 \pm 1.10$ & $0.34 \pm 1.34$ & $0.35 \pm 1.15$ & $0.34 \pm 1.25$ & $0.34 \pm 1.32$ & $0.34 \pm 1.22$ \\
\hline 2 & $0.16 \pm 1.32$ & $0.15 \pm 1.25$ & $0.14 \pm 1.24$ & $0.15 \pm 1.35$ & $0.16 \pm 1.28$ & $0.14 \pm 1.34$ & $0.14 \pm 1.41$ & $0.14 \pm 1.37$ & $0.15 \pm 1.28$ \\
\hline 3 & $0.11 \pm 1.12$ & $0.10 \pm 1.05$ & $0.11 \pm 1.12$ & $0.10 \pm 1.25$ & $0.11 \pm 1.35$ & $0.10 \pm 1.41$ & $0.10 \pm 1.39$ & $0.11 \pm 1.38$ & $0.11 \pm 1.25$ \\
\hline 4 & $0.56 \pm 0.55$ & $0.55 \pm 0.56$ & $0.56 \pm 0.45$ & $0.55 \pm 0.49$ & $0.56 \pm 0.52$ & $0.55 \pm 0.44$ & $0.54 \pm 0.53$ & $0.53 \pm 0.47$ & $0.53 \pm 0.25$ \\
\hline 5 & $1.33 \pm 0.67$ & $1.32 \pm 0.56$ & $1.33 \pm 0.58$ & $1.32 \pm 0.46$ & $1.33 \pm 0.57$ & $1.32 \pm 0.48$ & $1.33 \pm 0.48$ & $1.32 \pm 0.51$ & $1.30 \pm 0.50$ \\
\hline 6 & $0.34 \pm 0.82$ & $0.34 \pm 0.92$ & $0.33 \pm 0.82$ & $0.34 \pm 0.81$ & $0.33 \pm 0.86$ & $0.33 \pm 0.89$ & $0.32 \pm 0.91$ & $0.33 \pm 0.89$ & $0.33 \pm 0.89$ \\
\hline 7 & $0.60 \pm 0.46$ & $0.59 \pm 0.49$ & $0.60 \pm 0.47$ & $0.59 \pm 0.48$ & $0.59 \pm 0.48$ & $0.60 \pm 0.46$ & $0.59 \pm 0.47$ & $0.60 \pm 0.43$ & $0.59 \pm 0.44$ \\
\hline 8 & $0.37 \pm 0.44$ & $0.38 \pm 0.45$ & $0.38 \pm 0.39$ & $0.39 \pm 0.34$ & $0.37 \pm 0.24$ & $0.39 \pm 0.29$ & $0.38 \pm 0.31$ & $0.39 \pm 0.33$ & $0.38 \pm 0.34$ \\
\hline 9 & $0.22 \pm 0.96$ & $0.21 \pm 0.92$ & $0.21 \pm 0.90$ & $0.22 \pm 0.94$ & $0.21 \pm 0.95$ & $0.22 \pm 0.92$ & $0.21 \pm 0.93$ & $0.22 \pm 0.94$ & $0.21 \pm 0.97$ \\
\hline 10 & $0.50 \pm 0.46$ & $0.49 \pm 0.54$ & $0.49 \pm 0.52$ & $0.49 \pm 0.49$ & $0.50 \pm 0.52$ & $0.48 \pm 0.34$ & $0.50 \pm 0.58$ & $0.48 \pm 0.59$ & $0.48 \pm 0.59$ \\
\hline
\end{tabular}

All data were presented as mean \pm standard deviation of three replications. The oil samples were irradiated at the intensity of $3500 \mu \mathrm{W} / \mathrm{cm}^{2}$.

tion technology did not increase the oil temperature.

\section{DISCUSSION}

In this study, we investigated the reduction of AFB1 in the UV-LED-treated unrefined groundnut oils. UV-LED irradiation technology used in the AFT degradation machine could significantly reduce the concentrations of AFB1 in the unrefined groundnut oils $(p<0.05)$. Despite the reduction in levels of
AFB1 in the unrefined groundnut oils, our findings showed that UV-LED irradiation did not significantly alter the fatty acid compositions, acid and peroxide values of the oils $(p>0.05)$. However, there was a slight increase in total saturated fatty acids (34.9\%) in the treated oil samples after 20-min irradiation compared to the untreated oil sample $(32.49 \%)$. It is because UV irradiation altered the double bonds of some unsaturated fatty acids, especially elaidic
(A)

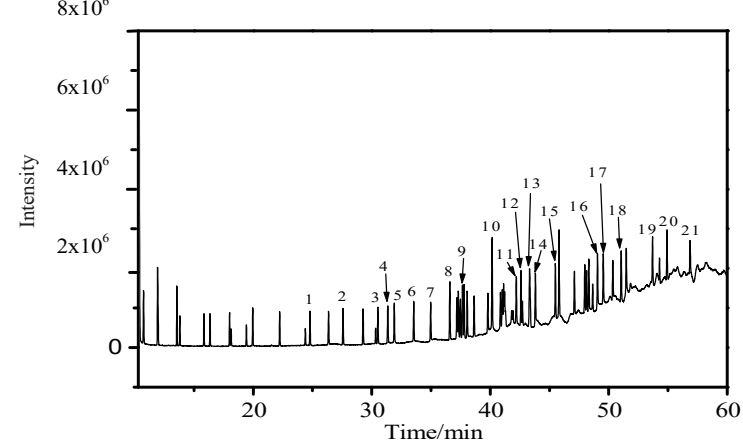

(B)

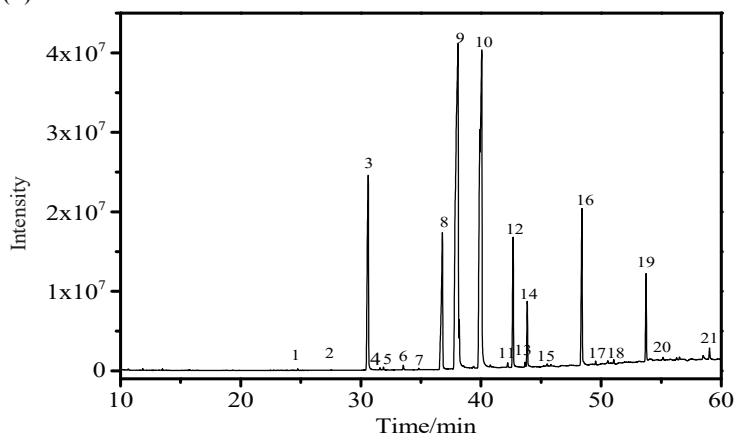

Fig. 3 GC-MS chromatograms of (A) FAME standards and (B) fatty acid methyl esters in groundnut oil. The fatty acids were identified as Peak 1-Peak 21 (Table 5). 
Table 5 Fatty acid compositions of unrefined groundnut oils treated at different irradiation times.

\begin{tabular}{|c|c|c|c|c|c|c|c|c|c|c|}
\hline \multirow{2}{*}{$\begin{array}{l}\text { Peak } \\
\text { No. }\end{array}$} & \multicolumn{3}{|c|}{ Fatty acid } & \multirow{2}{*}{$\begin{array}{l}\text { Retention } \\
\text { time (min) }\end{array}$} & \multicolumn{6}{|c|}{ Concentration (\%) } \\
\hline & & & & & $0 \mathrm{~s}$ & $30 \mathrm{~s}$ & $60 s$ & $300 \mathrm{~s}$ & $600 \mathrm{~s}$ & $1200 \mathrm{~s}$ \\
\hline 1 & Tetradecanoic acid, methyl ester & Myristic acid & C14:0 & 24.75 & 0.04 & 0.05 & 0.05 & 0.06 & 0.05 & 0.05 \\
\hline 2 & Pentadecanoic acid, methyl ester & $\begin{array}{l}\text { Pentadecyclic } \\
\text { acid }\end{array}$ & $\mathrm{C} 15: 0$ & 27.54 & 0.01 & 0.02 & 0.01 & 0.01 & 0.01 & 0.02 \\
\hline 3 & Hexadecanoic acid, methyl ester & Palmitic acid & C16:0 & 30.61 & 10.09 & 11.3 & 11.29 & 11.34 & 11.25 & 11.27 \\
\hline 4 & $\begin{array}{l}\text { cis-9-Hexadecenoic acid, } \\
\text { methyl ester }\end{array}$ & Palmitoleic acid & C16:1,n-7 & 31.60 & 0.05 & 0.08 & 0.07 & 0.09 & 0.07 & 0.07 \\
\hline 5 & $\begin{array}{l}\text { trans-9-Hexadecenoic acid, } \\
\text { methyl ester }\end{array}$ & $\begin{array}{l}\text { trans-Palmitoleic } \\
\text { acid }\end{array}$ & C16:1,n-7 & 31.88 & 0.07 & 0.10 & 0.10 & 0.10 & 0.09 & 0.10 \\
\hline 6 & Heptadecanoic acid, methyl ester & Margaric acid & C17:0 & 33.53 & 0.12 & 0.18 & 0.16 & 0.18 & 0.17 & 0.17 \\
\hline 7 & $\begin{array}{l}\text { cis-10-Heptadecenoic acid, } \\
\text { methyl ester }\end{array}$ & $\begin{array}{l}\text { Heptadecenoic } \\
\text { acid }\end{array}$ & $\mathrm{C} 17: 1, \mathrm{n}-7$ & 34.82 & 0.04 & 0.06 & 0.06 & 0.06 & 0.06 & 0.06 \\
\hline 8 & Octadecanoic acid, methyl ester & Stearic acid & 1 & 79 & 7.95 & 9.59 & 9.47 & 9.54 & 9.44 & 9.43 \\
\hline 9 & hyl ester & Ole & 9 & & 35.35 & 34.3 & 34.44 & 34.3 & 34.43 & 34.4 \\
\hline 10 & $\begin{array}{l}\text { All-cis-9,12-Octadecadienoic acid, } \\
\text { methyl ester }\end{array}$ & Linoleic acid & C18: & 0.06 & 29.68 & 27.8 & 27.85 & 27.69 & 28.01 & 28.1 \\
\hline 11 & $\begin{array}{l}\text { All-cis-9,12,15-Octadecatrienoic } \\
\text { acid, methyl ester }\end{array}$ & c acid & $\mathrm{C} 1 \varepsilon^{2}$ & 2 & 0.13 & 0.13 & 0.13 & 0.14 & 0.13 & 0.13 \\
\hline 12 & Eicosenoic acid, methyl ester & Ara & 20 & 67 & 4.58 & 4.54 & 4.54 & 4.61 & 4.51 & 4.45 \\
\hline 13 & cis-5-Eicosenoic acid, methyl ester & $\begin{array}{l}\text { 5-Eicosenoic } \\
\text { acid }\end{array}$ & C20: & 57 & 0.14 & 0.14 & 0.14 & 0.15 & 0.14 & 0.14 \\
\hline 14 & cis-1 & Gondo & $\mathrm{C} 2$ & & 1.95 & 1.94 & 1.91 & 1.88 & 1.90 & 1.90 \\
\hline 15 & Heneicosanc & $\begin{array}{l}\text { Heneicosylic } \\
\text { acid }\end{array}$ & $\mathrm{C} 21$ & 5.50 & 0.06 & 0.07 & 0.06 & 0.06 & 0.06 & 0.06 \\
\hline 16 & Docosan & Behenic acid & C22:0 & 48 & 6.27 & 6.33 & 6.33 & 6.34 & 6.31 & 6.24 \\
\hline 17 & $\begin{array}{l}\text { trans-13-Docosenoic acid, } \\
\text { methyl ester }\end{array}$ & Bra & $\mathrm{C} 2$ & & 0.10 & 0.11 & 0.10 & 0.10 & 0.10 & 0.10 \\
\hline 18 & Trico & & & & 0.1 & 0.11 & 0.11 & 0 . & 0.11 & 0.11 \\
\hline 19 & Tetr & & & & 2.83 & 2.78 & 2.77 & 2. & 2.74 & 2.68 \\
\hline 20 & Pent & cid & $\mathrm{C} 25$ & 56 & 0.06 & 0.07 & 0.06 & 0.11 & 0.06 & 0.07 \\
\hline 21 & Hexacosanoic acid, methyl ester & Cerotic acid & C26:0 & 59.02 & 0.37 & 0.38 & 0.35 & 0.39 & 0.36 & 0.35 \\
\hline
\end{tabular}

All data were presented as means of two replicates. The oil samples were irradiated at the intensity of $3500 \mu \mathrm{W} / \mathrm{cm}^{2}$.

acid and petroselaidic acid [21]. Elaidic acid is the stereoisomer of oleic acid, where oleic acid is the major monounsaturated fatty acid in groundnut oil. These fatty acids (oleic, elaidic and petroselaidic acids) share the same molecular weight of $282.46 \mathrm{~g} / \mathrm{mol}$.

On the other hand, the unrefined groundnut oils could be adulterated with animal fat. The GCMS data show that pentadecanoic (C15:0), heneicosanoic (C21:0), tricosanoic (C23:0) and pentacosanoic (C25:0) acids were detected in the oil samples. These saturated fatty acids are not commonly found in vegetable oils. Therefore, future studies need to focus on the adulteration of groundnut oil with animal fats on top of the AFB1 detoxification. Although the quality of the unrefined groundnut oil is maintained, degradation products of AFB1 are still needed to be identified, especially the in vivo toxicity and mutagenicity of the components. A previous study identified the degradation products of AFB1 in groundnut oil treated with UV irradiation as compounds $\mathrm{P} 1\left(\mathrm{C}_{18} \mathrm{H}_{33} \mathrm{~N}_{3} \mathrm{O}_{3}\right)$ and $\mathrm{P} 2$ $\left(\mathrm{C}_{12} \mathrm{H}_{22} \mathrm{~N}_{2} \mathrm{O}_{2}\right)$ [22]. These compounds have lower toxicity levels than AFB1 $\left(\mathrm{C}_{17} \mathrm{H}_{12} \mathrm{O}_{6}\right)$.

AFT contamination in food occurs mainly due to high temperature and humid conditions. The levels of AFB1 detected in groundnut extracts ranged from $0.559-1.550 \mu \mathrm{g} / \mathrm{g}$ extract [23]. It is far higher than the levels determined in other nuts and grains [24]. In a recent study, two biodegraded products of AFB1 obtained from treatment with culture supernatant of Cladosporium uredinicola were structurally identified as $\mathrm{C}_{19} \mathrm{H}_{18} \mathrm{O}_{10}$ and $\mathrm{C}_{18} \mathrm{H}_{14} \mathrm{O}_{7}$; these compounds were reported to be less toxic than AFB1 based on quantitative structure-activity relationship and cytotoxicity experiment [25]. Besides the concern for AFT contamination and its impacts on consumer health, it is necessary to take preventive and proper measures to reduce the levels of contamination below the regulatory limits.

Literature has shown that gamma irradiation inhibited the growth of aflatoxigenic moulds on corn seeds, thus reduced AFB1 formation [26]. Gamma irradiation also effectively reduced AFT accumulation in black and white peppers regardless of the moisture content of peppers [27]. In contrast, Di Stefano et al [28] reported that gamma irradiation reduced tocopherol content in almond at increasing irradiation doses. In addition to gamma irradiation, temperature-controlled pulsed light treatment has been shown to reduce AFT levels in treated groundnut oils. However, there is a limitation in using 
this method due to the high temperature generated during the irradiation. The results showed that the oil's temperature increased from $26^{\circ} \mathrm{C}$ to $220^{\circ} \mathrm{C}$ during the 10-min temperature-controlled pulsed light treatment [29]. The high temperature reduced the oil quality by elevating the peroxide value, acid value and percentage of free fatty acid in the oil after $400 \mathrm{~s}$ irradiation. In contrast, inactivation of AFB1 in groundnuts using pulse light for $300 \mathrm{~s}$ at $5 \mathrm{~cm}$ distance caused a burnt surface without affecting the groundnut's quality [30].

Advancement in UV technology replaces the traditional ways to detoxify AFTs in nuts and grains. UV irradiation has been discovered for its use in the detoxification of AFB1 in nuts due to their photosensitivity [31]. In the past, UV-C has been applied in the removal of AFT in nut samples. Basaran reported that a single dose ( $6 \mathrm{~h}$ irradiation) of UV-C treatment sufficiently reduced almost $25 \%$ of AFB1 in the treated hazelnut without affecting its sensory properties [32]. The review by Diao et al [12] showed that UV irradiation with different irradiation conditions effectively reduced more than $86 \%$ of AFT in groundnut oil. Moreover, UV irradiation has been reported to reduce polyphenol oxidase activity [33]. Thus, it helps to protect polyphenols in the oil sample. The findings of this study indicate that UV-LED irradiation effectively reduces the levels of AFB1 in the unrefined groundnut oils. The application of UV-LED irradiation technology in detoxification of AFB1 in groundnut oil is a more promising way compared with the use of other methods. It is also an economical way for the food processing industry to reduce AFT contamination in oils and other food products. However, UV detoxification efficiency is still the focal point. Development of advanced equipment will be necessary for food protection in the future.

\section{CONCLUSION}

Detoxification of AFTs by UV-LED irradiation technology is an innovative way of maintaining the quality of groundnut oils. The UV-LED detoxification system is considered being a green technology, where it generates low heat. Thus, it does not destroy unsaturated fatty acids of groundnut oils. UV-LED irradiation duration and intensity were the two factors that affect AFB1 content in the unrefined groundnut oils. The degradation of AFB1 was dependent on irradiation time and intensity. UVLED irradiation also did not alter acid and peroxide values and fatty acid compositions of the treated oil samples compared with the untreated.
Acknowledgements: We are grateful to the leaders of Guangxi Zhuang Autonomous Region and Guangxi Academy of Agricultural Sciences for providing us with the funding, Outstanding Discipline Team Project of Guangxi Academy of Agricultural Sciences (Gui Agricultural Science 2018YT26). We would also like to thank Say Wah Lee from Shanghai Jiao Tong University for her help to proofread the paper.

\section{REFERENCES}

1. Bryden WL (2007) Mycotoxins in the food chain: human health implications. Asia Pac J Clin Nutr 16, 95-101.

2. Kumar P, Mahato DK, Kamle M, Mohanta TK, Kang SG (2017) Aflatoxins: a global concern for food safety, human health and their management. Front Microbiol 15, 83-85.

3. Samarajeeewa U, Sen AC, Cohen MD, Wei CI (1990) Detoxification of aflatoxins in foods and feeds by physical and chemical methods. $J$ Food Prot 53, 489-501.

4. Hamid AB (1997) Aflatoxin contamination problems in groundnut in Asia. In: Mehan VK, Gowda CLL (eds) Aflatoxin Contamination Problems in Groundnut in Asia: Proceedings of the First Asia Working Group Meeting, Ministry of Agriculture and Rural Development, Hanoi, Vietnam, pp 32-35.

5. Idris YM, Mariod AA, Elnour IA, Mohamed AA (2010) Determination of aflatoxin levels in Sudanese edible oils. Food Chem Toxicol 48, 2539-2541.

6. Fan YY, Ou SF (2020) Advances in research on pollution status and risk assessment of aflatoxin B1 in edible vegetable oils in China. Occup Health 36, 701-705.

7. Song M, Le L, Luo Y, Xie C, Chen Z (2019) Dietary exposure and risk assessment of aflatoxin $\mathrm{B} 1$ in peanut oil produced by individual workshop in Guangdong. Chin Oil Fat 44, 96-101.

8. Vankayalapati VK (2018) Aflatoxins: properties, toxicity and detoxification. Nutr Food Sci 6, 1-4.

9. Eshelli M, Harvey L, Edrada-Ebel R, Mcneil B (2015) Metabolomics of the bio-degradation process of aflatoxin $\mathrm{B} 1$ by actinomycetes at an initial $\mathrm{pH}$ of 6.0. Toxins 7, 439-456.

10. Smita T, Mishra HN (2011) Modeling and optimization of enzymatic degradation of aflatoxin B1 (AFB1) in red chili powder using response surface methodology. Food Bioproc Tech 4, 770-780.

11. Hinds LM, O'Donnell CP, Akhter M, Tiwari BK (2019) Principles and mechanisms of ultraviolet light emitting diode technology for food industry applications. Innov Food Sci Emerg Technol 56, 1-9.

12. Diao E, Li X, Zhang Z, Ma W, Ji N, Dong H (2015) Ultraviolet irradiation detoxification of aflatoxins. Trends Food Sci Technol 42, 64-69.

13. Patras A, Julakanti S, Yannam S, Bansode RR, Burns 
M, Vergne MJ (2017) Effect of UV irradiation on aflatoxin reduction: a cytotoxicity evaluation study using human hepatoma cell line. Mycotoxin Res 33, 343-350.

14. Diao E, Shen X, Zhang Z, Ji N, Ma W, Dong H (2015) Safety evaluation of aflatoxin B1 in peanut oil after ultraviolet irradiation detoxification in a photodegradation reactor. Int J Food Sci Technol 50, 41-47.

15. Yousef AE, Marth EH (1986) Use of ultraviolet energy to degrade aflatoxin $M_{1}$ in raw or heated milk with and without added peroxide. J Dairy Sci 69 , 2243-2247.

16. Khan AI (2013) A GC-FID method for the comparison of acid-and base-catalyzed derivatization of fatty acids to FAMEs in three edible oils. In: Application Note 20733, Thermo Fisher Scientific, Runcorn, UK, pp 1-8.

17. Choo PY, Azlan A, Khoo HE (2018) Cooking methods affect total fatty acid composition and retention of DHA and EPA in selected fish fillets. Sci Asia 44, 92-101.

18. Hussin SN, Azlan A, Khoo HE, Kadir NAAA, Razman MR (2019) Comparison of fat composition and chemical properties of fat extracts between fish fillets of selected warm-water and cold-water fish. BioSci J 35, 1968-1978.

19. AOCS (1989) AOCS Official Method Ca 5a-40. In: Official Methods and Recommended Practices, 4th edn, AOCS Press, Champaign.

20. AOCS (1989) AOCS Official Method Cd 8b-90. In: Official Methods and Recommended Practices, 4th edn, AOCS Press, Champaign.

21. Peltonen JPK, He P, Rosenholm JB (1993) Influence of UV irradiation on unsaturated fatty acid monolayers and multilayer films: X-ray diffraction and atomic force microscopy study. Langmuir 9, 2363-2369.

22. Mao J, He B, Zhang L, Li P, Zhang Q, Ding X, Zhang $\mathrm{W}$ (2016) A structure identification and toxicity assessment of the degradation products of aflatoxin B1 in peanut oil under UV irradiation. Toxins 8, ID 332.

23. Koonanuwatchaidet P, Fong LYY (1980) Determina- tion of aflatoxin B1 in groundnut extracts and its mutagenicity. J Sci Soc Thailand 6, 143-145.

24. Darwish WS, Ikenaka Y, Nakayama SMM, Ishizuka M (2014) An overview on mycotoxin contamination of foods in Africa. $J$ Vet Med Sci 76, 789-797.

25. Ernuo T, Xin D, Wenhao C, Changgao W, Jianguo L, Cai J (2020) Structure and toxicity analysis of aflatoxin B1 biodegraded products by culture supernatant of Cladosporium uredinicola. Sci Asia 46, 308-314.

26. Markov K, Mihaljević B, Domijan AM, Pleadin J, Delaš F, Frece J (2015) Inactivation of aflatoxigenic fungi and the reduction of aflatoxin B1 in vitro and in situ using gamma irradiation. Food Control 54, 79-85.

27. Jalili M, Jinap S, Noranizan MA (2012) Aflatoxins and ochratoxin a reduction in black and white pepper by gamma radiation. Radiat Phys Chem 81, 1786-1788.

28. Di Stefano V, Pitonzo R, Bartolotta A, D'Oca MC, Fuochi P (2014) Effects of $\gamma$-irradiation on the $\alpha$ tocopherol and fatty acids content of raw unpeeled almond kernels (Prunus dulcis). LWT 59, 572-576.

29. Abuagela MO, Iqdiam BM, Baker GL, MacIntosh AJ (2018) Temperature-controlled pulsed light treatment: impact on aflatoxin level and quality parameters of peanut oil. Food Bioproc Tech 11, 1350-1358.

30. Abuagela MO (2017) Inactivation of aflatoxins B1, $\mathrm{B} 2$ in peanuts by pulsed light (PL). PhD thesis, Univ of Florida, USA.

31. Jubeen F, Bhatti IA, Zahhoor-ul-hassan MZK, Shahid M (2012) Effect of UVC irradiation on aflatoxins in ground nut (Arachis hypogea) and tree nuts (Juglans regia, Prunus duclus and Pistachio vera). J Chem Soc Pak 34, 1366-1374.

32. Basaran P (2009) Reduction of Aspergillus parasiticus on hazelnut surface by UV-C treatment. Int J Food Sci Technol 44, 1857-1863.

33. Falguera V, Pagan J, Garza S, Garvin A, Ibarz A (2011) Ultraviolet processing of liquid food: A review: Part 2: Effects on microorganisms and on food components and properties. Food Res Int 44, 1580-1588. 